\title{
Somogy megye tapogatósbogarainak és gödörkésbogarainak katalógusa (Coleoptera: Staphylinidae: Pselaphinae, Scydmaenidae)
}

\author{
RUDNER JÓZSEF
}

RUdNER J.: Catalogue of the Staphylinidae: Pselaphinae and Scydmaenidae (Coleoptera) from Somogy county, Hungary

Abstract: Locality data of 33 Pselaphinae and 19 Scydmaenidae species are given from Somogy county.

\section{Bevezetés}

A Fauna Regni Hungariae Coleoptera-kötetében (KUTHY 1897) sem a tapogatósbogarakból (Staphylinidae: Pselaphinae), sem a gödörkésbogarakból (Scydmaenidae) nem találunk Somogy megyei lelóhelyadatot. A megye területéról mind a tapogatósbogarakat ( 1 faj) mind pedig a gödörkésbogarakat (2 faj) elôször PolinszKY (1886) említi meg. További Pselaphinae adatokat (egy faj két alfaja) találunk még BesucHeT (1963), illetve Horvatovich (1982) (1 faj) munkájában.

A gödörkésbogarakról írt határozójában CSIKI (1909) az egyik fajnál megemlíti Boglárt (=Balatonboglár) mint lelóhelyet. Közel 70 évet kell várni a család újabb faunisztikai adataira, amikor is HoRVATOVICH $(1980,1981)$ két tanulmányában is feltúnnek Somogy megyei lelóhelyadatok (4 faj).

A megye tapogatósbogár- és gödörkésbogár-faunájáról (12 illetve 10 faj) a legtöbb információt a közelmúltban megjelent Duna-Dráva Nemzeti Park faunáját feldolgozó munkában találjuk (RUDNER 1998). Mindezeket összegezve 1998-ig a megyéból 15 Pselaphinae és 17 Scydmaenidae-faj volt ismeretes.

A Magyar Természettudományi Múzeum és a Janus Pannonius Múzeum gyưjteményének folyamatos feldolgozása során azonban mind újabb és újabb fajok kerülnek eló. Itt külön meg kell említenem Lichtneckert Ferenc siófoki lelóhelyezésú állatait, amelyek több kolléga szerint is nagy valószínúséggel tartalmaznak téves adatokat. Az eddig meghatározott közel másfélezer tapogatósbogár közt azonban még nem találtam egyetlen egy olyan fajt sem, amely megkérdójelezhetné a lelóhelyek hitelességét, így természetesen mind fel is került a listára.

A jelen dolgozatban 33 tapogatósbogárfaj és 19 gödörkésbogárfaj Somogy megyei adata szerepel. Ezek közül kiemelendó a Trimium lichtneckerti Machulka, 1935, amely Siófokról lett leírva, és a Cephennium (Cephennium) paganettii Besuchet, 1971, melynek egyik paratípusa szintén siófoki. Faunisztikai érdekesség a Brachygluta xanthoptera xanthoptera (Reichenbach, 1816), ennek a taxonnak hiteles hazai adatai ugyanis eddig csak Somogy megyéból ismeretesek. 
Az irodalomban már közölt adatokat a jelen tanulmányban nem ismétlem meg, csupán az irodalmi forrásra hivatkozom. Az eddig nem publikált adatokat azonban részletesen felsorolom.

\section{A Somogy megyéból ismert fajok jegyzéke}

\section{A listában használt rövidítések:}

Gyưitők nevei: ÁL = Ádám László, EYS = Endrôdy-Younga Sebestyén, HE = Hámori Edit, $\mathrm{HS}=$ Horvatovich Sándor, $\mathrm{KI}=$ Kovács I., KoL = Kovács L., KZ = Kaszab Zoltán, MiO = Mihók Ottó, PA = Podlussány Attila, SJ = Sár József, SV = Stiller Viktor, SZV = Székessy Vilmos.

Gyújtési módok: e. = egyelés, ecs. = esti csapkodás, fh. = fúhálózás, fut. = futtatás, lp. = lámpázás, $\mathrm{r}$. = rostálás, acs. = alkonyati csapkodás, $(\mathrm{x})=$ példányszám.

Gyújtemény, ahol a példány található: JPM = Janus Pannonius Múzeum, Pécs, MTM = Magyar Természettudományi Múzeum, Budapest.

\section{Staphylinidae}

Pselaphinae

Bibloplectus ambiguus (Reichenbach, 1816) Rudner (1998: 240).

Euplectus karsteni (Reichenbach, 1816) Polinszky (1886: 147) Euplectes Karsteni néven.

Trimium brevicorne (Reichenbach, 1816) Rudner (1998: 240). Barcs: Ósborókás, 1979.XI.10., HS (1), JPM; Barcs: Ósborókás, égeres, 1979.III.09., HS \& SJ (1), JPM, 1979.III.24., HS \& SJ (2), JPM; Barcs: Ósborókás, tölgyes, 1979.VIII.23., HS (1), JPM. Darány, 1979.XI.10., HS (1), JPM; Darány, avar, 1978.I.31., HS (r.1), JPM; Darány: örház, moha, 1978.1.31., HS (1), JPM; Darány, temetô, avar, 1978.1.31., HS (r.3), JPM.

Trimium lichtneckerti Machulka, 1935 - Siófok (locus typicus), Lichtneckert (1 típuspéldány), MTM.

Trichonyx sulcicollis (Reichenbach, 1816) Somogy megye, (1), MTM. Kálmáncsa, 19l4.IV., SV (1), MTM. Siófok, Lichtneckert (25), MTM.

Amauronyx maerkelii (Aubé, 1844) - Siófok, (1), MTM; Siófok, Lichtneckert (20), MTM.

Batrisus formicarius Aubé, 1833 - Siófok, Lichtneckert (4), MTM.

Batrisodes delaportei (Aubé, 1833) - Rudner (1998: 240).

Batrisodes exculptus (Hampe, 1850) Rudner (1998: 240).

Bythinus acutangulus acutangulus Reitter, 1878 - Zamárdi: Töreki-láp, 1953.V.25., Kovács É. \& SZV (acs.2), MTM; Zamárdi: Újlaki- erdő, avar, 1953.V.06., KZ (r.3), MTM.

Bythinus reichenbachi (Machulka, 1928) Somogy megye, (1), MTM. Barcs: Ósborókás, 1979.XI.24., HS \& SI (1), JPM

Bryaxis bulbifer (Reichenbach, 1816) Rudner (1998: 240). Barcs: Ósborókás, 1972.X.23., HS (1), JPM; 1979.X.23., HS (12), JPM; Barcs: Ósborókás, égeres, 1979.III.09., HS \& SJ (1), JPM; 1979.III.24., HS \& SJ (1), JPM; Barcs: Ósborókás, zsombékos, 1979.VIII.17., HS \& SJ (r.l), JPM. Darány, avar, 1978.I.3I., HS (r.l), JPM; Darány, nádas, 1979.II.06., HS \& SJ (r. l), JPM.

Bryaxis carinula (Rey, 1888) - Somogy megye, (1), MTM. Barcs: Ósborókás, tölgyes, 1979.VIII.23., HS (2), JPM. Nagybajom, 1994.X.01., PA (1), MTM. Zamárdi: Zamárdierdö, 1953.X.07., HE \& Kovácsné (r.7), MTM; Zamárdi-erdó, cserjés, 1953.X.09., KZ (r.5), MTM; Zamárdi-erdő, erdôszél, 1953.X.09., KZ (r.5), MTM.

Bryaxis curtisi orientalis (Karaman, 1952) Rudner (1998: 240). Somogy megye, (2), MTM. Barcs: Barcsi Ósborókás, 1979.XI.10., HS (1), JPM; 1979.XI.10., HS \& SI (2), JPM; 1979.XI.24., HS \& SJ (1), JPM; Barcsi Ósborókás, gyertyános, 1979.II.24., HS \& S) (1), JPM; Barcsi Ósborókás, tölgyes, 1979.VIII.23., HS (3), JPM. Darány: Becse-hegy, 1995.IX.05,, PA (1), MTM. Kaposgyarmat-Hajmás, 1914.VI., SV (3), MTM. Kaposvár: Nádasdierdő, 1962.X.31., EYS (r.22), MTM. Nagybajom, 1962.X.30., EYS (r.1), MTM; 1994.X.01., PA (l), MTM. 
Bryaxis glabricollis glabricollis (SchmidtGoebel, 1836) - Rudner (1998: 240). Somogy megye, (7), MTM. Bélavár, 1995.IX.07-08., PA (2), MTM.

Rybaxis longicornis (Leach, 1817) - Rudner (1998: 240). Apáti, 1917., MiO (1), MTM. Barcs: Ösborókás, 1979.VIII.16., HS (3), JPM; Barcs: Ósborókás, nyíres, 1979.III.24., HS \& SJ (1), JPM. Darány: őrház, moha, 1978.I.31., HS (1), JPM. Kaposvár (Kaposfüred), Peregi (2), MTM. Siófok, Lichtneckert (329), MTM. Szentbalázs, SV (1), MTM. Vörs (Kisbalaton): erdő, 1950.III.20., KZ \& SZV (r.4), MTM; 1950.111.21., KZ \& SZV (r.7), MTM; 1950.X.16., SZV (r.3), MTM; Vörs (Kisbalaton): Gyékényes, 1950.VI.12-21., KoL (lp.l), MTM. Zamárdi: Töreki-láp, 1953.VII.26., KZ (ecs.3), MTM; Zamárdi: Zamárdi-erdő, cserjés, 1953.X.07., HE \& Kovácsné (r. l), MTM; 1953.X.09., KZ (r.l), MTM.

Brachygluta fossulata (Reichenbach, 1816) Somogy megye, (1), MTM. Balatonlelle (Boglárlelle), Peregi (5), MTM. Balatonöszöd (Öszöd), 1896., Ehmann (I), MTM; 1897.VIII., Ehmann (1), MTM. Darány, nádas, 1978.VII.0l., HS \& SJ (r.l), JPM. Hedrehely, 1977.VIII.08., HS (1), JPM. Kaposgyarmat-Hajmás, 1911.IV.19., SV (1), MTM. Kisbárapáti, SV (2), MTM. Siófok, Lichtneckert (140), MTM. Vörs (Kisbalaton): Gyékényestó, Vörsi-árok, árvíz, 1950.XI.0709., Kovács Lajos (fut.1), MTM; 1950.XI.14., Kovács Lajos (fut.3), MTM; 1950.XI.19., Kovács Lajos (fut.3), MTM. Zamárdi: Töreki-láp, szántók szélérôl, 1953.V.05. KZ (1), MTM.

Brachygluta haematica (Reichenbach, 1816) fajcsoport nőstényeinek lelöhelyadatai. - Kaposvár (Kaposfüred), Peregi (1), MTM. Siófok, Lichtneckert (77), MTM. Vörs (Kisbalaton): Cölömpös, nádtörmelék alól, $1951 . I n I .24 .$, Kovács Lajos (r. 1), MTM; Vörs (Kisbalaton): Gyékényes-tó, Vörsi-árok, 1950.XI.07-09., Kovács Lajos (fut.1), MTM.

Brachygluta haematica (Reichenbach, 1816) Csurgó (Besuchet 1963: 32). Siófok, Lichtneckert (38), MTM.

Brachyoluta simplicior Raffray, 1904 - Siófok, Lichtneckert (31), MTM. Vörs (Kisbalaton): Cölömpös, nádtörmelék alól, 1951.III.24., Kovács Lajos (1), MTM. Zamárdi: Töreki-láp, 1953.VII.25-26., KZ (ecs.2), MTM.

Brachygluta sinuata (Aubé, 1833) - Csurgó (Besuchet 1963: 31). Kaposvár (Kaposfüred), Peregi (1), MTM. Siófok, Lichtneckert (17), MTM.
Brachygluta helferi longispina (Reitter, 1884) Siófok, Lichtneckert (84), MTM.

Brachygluta lefebvrei lefebvrei (Aubé, 1833) Rudner (1998: 240). Csurgó, (9), MTM. Kaposvár, 1916.X.05., SV (2), MTM. Siófok, Lichtneckert (12), MTM.

Brachygluta retowskii Simon, 1883 - Ságvár, Lichtneckert (1), MTM. Siófok, Lichtneckert (10), MTM.

Brachygluta trigonoprocta (Ganglbauer, 1895) Kaposgyarmat-Hajmás, 19l4.VI., SV (1), MTM. Siófok, Lichtneckert (2), MTM.

Brachygluta xanthoptera xanthoptera (Reichenbach, 1816) - Rudner (1998: 240) Siófok, Lichtneckert (2), MTM.

Fagniezia impressa (Panzer, 1805) - Barcs: Ősborókás, 1979.V.16., HS (1), JPM; 1979.VIII.16., HS (1), JPM; 1979.XI.24., HS \& SJ (9), JPM; Barcs: Ősborókás, égeres, 1979.II.24., HS (2), JPM; Barcs: Ôsborókás, zsombékos, 1979.VIII.17., HS \& SJ (r.4), JPM. Boglárlelle (Balatonlelle), Peregi (1), MTM. Siófok, Lichtneckert (674), MTM. Vörs (Kisbalaton): Cölömpös, nádtörmelék alól, 1951.III.24., Kovács Lajos (1), MTM; Vörs (Kisbalaton), erdő, 1950.III.21., KZ \& SZV (r.l), MTM; 1950.X.16., SZV (r.1), MTM; Vörs (Kisbalaton): Gyékényestó, Vörsi-árok, árvíz, 1950.XI.07-09., Kovács Lajos (fut.2), MTM. Zamárdi: Balaton-part, detritus, 1953.IX.05., KZ (r.1), MTM; Balaton-part, ripicol, 1953.X.09-10., HE (2), MTM; Zamárdi: Töreki-láp, 1953.V.05., KI (e.1), MTM; 1953.V.07., KI (e.3), MTM; 1953.V.10., KI (e.1), MTM; 1953.V.24-26., Kovács Istvánné (fh.l), MTM; 1953.VII.25., KZ (ecs.2), MTM; 1953.VII.26., KZ (ecs.13), MTM; Töreki-láp, korhadt nyárfatönkből, 1953.V.08., KI (9), MTM; Töreki-láp, nyárfakéreg alól, 1953.V.08., KZ (1), MTM.

Trissemus antennatus serricornis (Schmidt, 1838) - Horvatovich (1982: 22) Reichenbachia antennata néven, Rudner (1998: 240). Darány, nádas, 1978.VII.01., HS \& SJ (r.1), JPM. Gyékényes: Nyárfás $(90 \mathrm{~m})$, Cypero-Juncetum bufonii, homokról, 1993.X.02., ÁL (1), MTM. Siófok, Lichtneckert (3), MTM.

Pselaphaulax dresdensis dresdensis (Herbst, 1792) - Rudner (1998: 240). Darány: ôrház, moha, 1978.I.31., HS (1), JPM. Siófok, Lichtneckert (6), MTM.

Pselaphus heisei Herbst, 1792 - Boglárlelle (Balatonlelle), Peregi (1), MTM. Siófok, Lichtneckert (5), MTM. Vörs (Kisbalaton): Gyékényestó, Vörsi-árok, árvíz, 1950.XI.07- 
09., Kovács Lajos (fut.1), MTM; 1950.XI.14., Kovács Lajos (fut.11), MTM; 1950.XI.19., KZ \& Kovács Lajos (fut. 121), MTM. Zamárdi: Töreki-láp, szántók széléról, 1953.V.05., KZ (4), MTM; Zamárdi: Zamárdi-erdô, 1953.X.07., HE \& Kovácsné (r.3), MTM; Zamárdi: Zamárdi-erdő, cserjés, 1953.X.09., KZ (r.48), MTM.

Ctenistes palpalis Reichenbach, 1816 - Siófok, Lichtneckert (27), MTM. Vizvár: Drávapart, 1995.IX.06-07., PA (1), MTM. Vörs (Kisbalaton): Áll. erdô, 1950.IX.05-12., KoL (lp. 1), MTM.

Tyrus mucronatus mucronatus (Panzer, 1805)Darány, temető, avar, 1978.1.31., HS (r.1), JPM. Siófok, Lichtneckert (4), MTM.

Claviger longicornis P. W. J. Müller, 1818 Zamárdi, Lichtneckert (1), MTM.

Claviger testaceus testaceus Preyssler, 1790 Balatonföldvár, Lichtneckert (1), MTM. Siófok, Lasius emarginatus, Tetramorium caespitum, hangyafajokkal, Lichtneckert (16), MTM.

\section{Scydmaenidae}

Euthiconus conicicollis (Fairmaire et

Laboulbene, 1854) - Horvatovich (1981: 75)

Euthinus [sic!] conicicollis néven.

Euthia scydmaenoides Stephens, 1830 Horvatovich (1980: 36).

Cephennium (Cephennium) majus Reitter, 1881 - Rudner (1998: 239).

Cephennium (Cephennium) delicatulum Reitter, 1879 - Boglár (=Balatonboglár) (Csiki 1909: 14). Siófok, Lichtneckert (8), MTM.
Cephennium (Cephennium) paganettii Besuchet, 1971 - Siófok, Lichtneckert (lparatypus), MTM.

Cephennium (Cephennium) slovenicum Machulka, 1931 - Siófok, Lichtneckert (1), MTM

Neuraphes (Neuraphes) angulatus (P. W. J. Müller et Kunze, 1822) - Rudner (1998: 239). Stenichnus (Cyrtoscydmus) collaris (P. W. J. Müller et Kunze, 1822) - Rudner (1998: 239). Stenichnus (Cyrtoscydmus) pusillus (P. W. J. Müller et Kunze, 1822) - Polinszky (1886: 147) Scydmaenus pusillus néven. Stenichnus (Cyrtosydmus) scutellaris (P. W. J. Müller et Kunze, 1822) - Rudner (1998: 239). Microscydmus minimus (Chaudoir, 1845) -

Rudner (1998: 239). Microscydmus nanus (Schaum, 1844) Horvatovich (1980: 36) Euconnus nanus néven. Euconnus (Cladoconnus) denticornis (P. W. ).

Müller et Kunze, 1822) - Rudner (1998: 239). Euconnus (Euconnus) fimetarius (Chaudoir, 1845) - Rudner (1998: 239).

Euconnus (Euconnus) hirticollis (Illiger, 1798)Horvatovich (1980: 36). Euconnus (Spanioconnus) wetterhali (Gyllenhal, 1813) - Rudner (1998: 239). Euconnus (Tetramelus) oblongus plitvicensis Machulka, 1928 - Rudner (1998: 239). Euconnus (Tetramelus) pubicollis (P. W. J. Müllet et Kunze, 1822) - Rudner (1998: 239). Scydmaenus (Cholerus) rufus P. W. J. Müller et Kunze, 1822 - Polinszky (1886: 147) Eumicrus rufus néven.

1. táblázat: A tapogatósbogarak (Staphylinidae: Pselaphinae) és a gödörkésbogarak (Scydmaenidae) Somogy megyéból, illetve Magyarországról ismert fajainak száma

\begin{tabular}{|l|c|c|}
\hline Csoport & $\begin{array}{c}\text { A Somogy megyébol ismert } \\
\text { fajok száma }\end{array}$ & $\begin{array}{c}\text { A Magyarországról ismert } \\
\text { fajok száma }\end{array}$ \\
\hline Pselaphinae & 33 & $\mathrm{~kb} .90$ \\
\hline Scydmaenidae & 19 & $\mathrm{~kb} .45$ \\
\hline Osszesen & 52 & $\mathrm{~kb} .135$ \\
\hline
\end{tabular}




\title{
Irodalom
}

BesuCHET, C. 1963: Notes sur quelques Brachygluta paléarctiques (Col. Pselaphidae). - Mitt. der Schweizer. Ent. Ges. 36(1-2): 27-46.

CSIKI, E. 1909: Magyarország bogárfaunája. Vezérfonal a magyar szent korona országainak területén elóforduló bogarak megismerésére. II. kötet. 1. füzet. - Budapest, 80 pp.

HorvNrovich, S. 1980: Hazánk faunájára új és ritka bogárfajok a Dél-és Nyugat-Dunántúlról II. (Coleoptera). - A Janus Pannonius Múz. Évk. 24 [1979]: 33-43.

HorVAiovich, S. 1981 : Hazánk faunájára új és ritka bogárfajok a Dél- és Nyugat-Dunántúlról III. (Coleoptera). - A Janus Pannonius Múz. Évk. 25 [1980]: 71-83.

HoRvNTOVICH, S. 1982: Hazánk faunááara új és ritka bogárfajok a Dél-és Nyugat-Dunántúlról IV. (Coleoptera). - A Janus Pannonius Múz. Évk. 26 [1981]: 19-32.

KUTHY, D. 1897: Coleoptera. - In: A Magyar Birodalom Állatvilága (Fauna Regni Hungariae). Királyi Magyar Természettudományi Társulat, Budapest, 213 pp.

POLINSZKY, E. 1886: Adatok Somogymegye bogárfaunájához. - Rovartani Lapok 3: 146-148.

Rudner, J. 1998: Leiodidae, Scydmaenidae and Staphylinidae: Pselaphinae (Coleoptera) from the Duna-Dráva National Park, South Hungary. - Dunántúli Dolgozatok Természetudományi Sorozat 9: 237-242.

\section{Catalogue of the Staphylinidae: Pselaphinae and Scydmaenidae (Coleoptera) from Somogy county, Hungary}

\section{JÓZSEF RUDNER}

The first data of Pselaphinae and Scydmaenidae from Somogy county are found in the early paper of POLINSZKY (1886). Other species of pselaphines were mentioned by BESUCHET (1963) (two subspecies of a species) and Horvatovich (1982) (one species).

CSIKI (1909) mentioned Boglár (=Balatonboglár) as a locality of one species of Scydmaenidae. We had to wait nearly 70 years for further data. Localities of four species from Somogy county are published in two contributions of HORVATOVICH $(1980,1981)$.

Most of the information on Pselaphinae (12 species) and Scydmaenidae (10 species) of the county is found in the recently published account of the fauna of the Duna-Dráva National Park (RUDNer 1998). Until 1998, based on the above mentioned works, 15 Pselaphinae and 17 Scydmaenidae species were known from Somogy county.

In the present paper, data of 33 Pselaphinae and 19 Scydmaenidae species from Somogy county are presented. Three taxa are worth mentioning. Trimium lichtneckerti Machulka, 1935 was described from Siófok. One of the paratypes of Cephennium (Cephennium) paganettii Besuchet, 1971 is also from Siofok. The only verified Hungarian data of Brachygluta xanthoptera xanthoptera (Reichenbach, 1816) are known from Somogy county.

\author{
Author's address \\ József RUDNER \\ Hungarian Natural History Museum \\ H-1088 Budapest \\ Baross u. 13 \\ HUNGARY
}

